\title{
RSP Revisitada Considerações sôbre o problema imigratório
}

\section{Carlos Dodsworth Machado}

Texto publicado na RSP, vol. 4, no 3, dez. de 1945.

Escrito em 1945, por Carlos Dodsworth Machado, o texto versa sobre o fenômeno da imigração em massa para o Brasil num momento da história em que existiam não somente demanda no mercado de trabalho brasileiro por mão de obra, como também a esperança de uma nova era econômica, algo que justificava a abertura do país à vinda de estrangeiros. Escrito há quase 70 anos, o artigo causa impacto pelo fato de retratar uma realidade do século XX bastante similar ao drama vivido pelo Estado contemporâneo, ressalvados, obviamente, o contexto e as proporções. Desta vez, os rostos europeus, árabes e nipônicos são substituídos por imigrantes de origem africana (especialmente vindos de países como Gana, Senegal, Nigéria, Cabo Verde e Angola), sul-americana (peruanos, bolivianos, paraguaios em sua maioria), chinesa e sul-coreana, bem como vindos da América Central, haja vista a imigração massiva de haitianos para estados como Acre, São Paulo e Paraná. Grande parte dessa imigração recente é feita de maneira ilegal. Fugindo da pobreza ou de conflitos bélicos em seus países, muitos imigrantes apresentam mão de obra pouco qualificada, o que os torna vítimas de condições de trabalho precárias. $O$ texto de Machado atesta que o Brasil se ressentia da ausência de uma organização administrativa capaz de arcar com as responsabilidades que acompanhavam a ampla introdução de imigrantes no país. Por isso, o autor ressalta a importância da presença de instituições e normas acautelatórias para a chegada desses imigrantes. Todavia, cabe destacar que, para Machado, era preciso saber aproveitar essa leva imigratória como trunfo rumo à tão sonhada prosperidade brasileira.

As condições atuais, dentro e fora de nossas fronteiras, atestam a marcha que o mundo realiza na direção de um novo estado de coisas, favorável à resolução de problemas brasileiros que afetam particularmente o nosso bem-estar social e econômico. 
O extraordinário desenvolvimento dos meios de transporte e comunicações reduziu de tal forma as distâncias, que novas concepções constituem condição fundamental para um proveitoso intercâmbio do progresso representado pela vulgarização das vitórias científicas sôbre os males físicos e pelos descobrimentos e invenções ampliadoras das possibilidades de conforto e bem-estar.

Unidos povos e nações na mobilização integral de recursos, e também nos multiformes padecimentos impostos pelo gigantesco conflito, aprendemos que, malgrado diferenças de raça, língua, religião e costumes, a humanidade é uma só e um só o seu problema: a implantação decisiva de um genuíno sentimento de fraternidade universal.

Ante as novas contingências que se delineiam, parece oportuno colocarmonos à altura dos acontecimentos, identificando e provendo racionalmente as necessidades que assolam a nossa estrutura social e econômica.

A pobreza demográfica de nossa pátria e a proximidade de empreendimentos carecedores, qualitativa e quantitativamente, de mão de obra, parecem reclamar a introdução imediata de largos contingentes imigratórios, a exemplo do que se vem verificando com outros países sul-americanos.

Os aspectos delicados que a questão oferece prestam-se a considerações bastante amplas, às quais somos levados mais pelo objetivo de encarecer a sua importância do que de versá-la com a segurança e proficiência dos que se acham de ofício incumbidos do seu tratamento.

Já nos períodos iniciais da história da humanidade, podem ser observados movimentos migratórios nos grupamentos humanos mais rudimentares, à cata de alimentos ou empenhados em movimentos coletivos de conquista e colonização.

A princípio francamente hostil, a atitude das sociedades, quanto à aceitação de elementos adventícios, variou através do tempo, ao sabor das contingências históricas.

Essa hostilidade, caracterizadora da atitude dos povos primitivos com relação aos estrangeiros, evoluiu lentamente no sentido de uma crescente tolerância, que culmina em Roma, com a introdução, na magistratura romana, da figura do "praetor peregrinus". Com efeito, não obstante originàriamente avêssa à integração de estranhos, a "urbs" institui estabelecimentos de beneficência destinados a acolher estrangeiros necessitados ("xenodochia"), marcando tais fatos, a nosso ver, o reconhecimento público da existência de direitos próprios do estrangeiro.

Essas tendências foram acentuadas pelo incremento das atividades de comércio, aliados à adoção dos princípios cristãos de fraternidade universal, 
elevando gradativamente a personalidade do alienígena, até quase nivelá-lo à situação do nacional.

O tema é vasto demais para enquadrar-se nos limites de um ponto de vista exclusivamente jurídico, o que daria uma visão unilateral do problema imigratório. Prende-se a outros ramos de conhecimento, eriçando-se das dificuldades próprias das ciências sociais.

Daí o não se poder, como faz Espínola, considerar a Revolução Francesa como o marco principal da história das migrações no mundo, atribuindo-lhe a virtude de haver dissipado as prevenções existentes contra os estrangeiros, quando na realidade aquêle movimento veio apenas reconhecer uma situação que já se vinha verificando anteriormente ${ }^{1}$.

\footnotetext{
1 Tais são as palavras do mestre: "Foi a Revolução Francesa, com a violenta transformação das condições sociais, operada sob o influxo das idéias filosóficas da época e do proselitismo incomedido, através das ondas de sangue das vítimas de uma reação insaciável, imoladas nas confusões do terror, que teve a virtude de dissipar as prevenções contra os estrangeiros, admitindo-os a compartilhar, por toda parte, dos próprios direitos reconhecidos aos nacionais, sem preconceitos, e, em muitos Estados, até, sem preocupações de reciprocidade legislativa ou diplomática". - (Eduardo Espínola e Eduardo Espínola Filho
} - Tratado de Direito Civil Brasileiro - Vol. VI, Ed. Freitas Bastos, 1938, pag. 236).

O Sr. Estanislau Fischlowitz, que durante 18 meses pôs, no D.A.S.P . , a serviço da Administração Pública Brasileira, a sua esplêndida cultura, refere-se ao assunto nos seguintes termos: “O princípio da liberdade das migrações foi proclamado pela revolução francesa e depois aplicado paralelamente ao liberalismo industrial, praticado, não somente na regulamentação interna, como também em relação às trocas internacionais de mercadorias e capitais" - (Estanislau Fischlowitz - "Migrações - problema internacional", in Revista do Serviço Publico, dezembro 1943, pag. 43).

Como vemos, 1789, proclamou o princípio da liberdade das migrações, mas não veio dissipar a prevenção contra o estrangeiro, pois esta foi exacerbada durante a guerra, em face das atividades dos países totalitários empenhados em aproveitar os seus imigrantes como " vanguarda de suas agressões e imperialismos", no dizer de Fischlowitz.

Também a prevenção contra o estrangeiro não foi dissipada pela Revolução Francesa, porque já vinha ela de longa data sofrendo abrandamentos sensíveis, como se poderá verificar nas afirmativas de Clóvis Bevilacqua (Direito das Obrigações - Ed. Freitas Bastos, 1931, pag.45), de que mesmo antes de reconhecidos os direitos dos estrangeiros, inventou-se um derivativo no instituto da hospitalidade. E citando Ihering: "No tempo da completa incapacidade jurídica do estrangeiro, a hospitalidade era a única forma dos contratos pessoais, entre pessoas pertencentes a comunidades diversas. À hospitalidade ligava-se todo o comércio internacional ou, mesmo, todo o movimento mercantil. Devia, portanto, ser o mais veemente empenho de uma comunidade, que não queria excluir-se de tôdas as relações com o mundo exterior, proteger o negociante estrangeiro que vinha ao país com suas mercadorias. A estrada devia ser franqueada ao mercador estrangeiro, do contrário ele não viria. Garantir-lhe a livre passagem era a condição essencial para atraí-lo. Esta livre passagem assegurava-lhe a hospitalidade que fazia, às vêzes, do salvo-conduto da idade média". 
Reconhecidos aquêles direitos fundamentais que haviam sido durante tanto tempo negados, o período é da mais absoluta liberdade, e a imprevisão e indiferença gerais, quanto às migrações, iriam produzir as tão lastimáveis conseqüências que se seguiram.

Foi por volta de 1850 que grandes massas imigratórias se canalizaram para os Estados Unidos, transpondo o oceano por fôrça das perseguições religiosas e raciais, da fome, da pobreza, e das facilidades propiciadas pelos naturais americanos, desejosos de vender terras e passagens.

John Commons, na sua interessante obra intitulada "Race and Immigrants in America", passa em revista os fatôres que influíram na formação daquela corrente imigratória, enunciando também os seus salutares efeitos sôbre a vida norteamericana.

A iniciativa particular predominou francamente, em razão das possibilidades que o braço estrangeiro vinha oferecer aos seus inescrupulosos exploradores. Organizaram-se várias companhias para introduzir imigrantes, e a influência dos motivos mercenários que norteavam a sua ação trouxe uma série de inconvenientes, tornando-se inclusive, a causa de futuros desajustamentos sociais.

Os governos iam-se deixando ficar à margem do problema e, quando não permaneciam em atitude passiva, limitavam-se a comprar colônias, providenciar a instalação dos imigrantes, firmar tratados e editar disposições administrativas internas, quando a verdadeira atitude cabível seria encarregar-se da direção sistemática de todo o aparelho imigratório, transformando a imigração, "de função do indivíduo, em função do Estado".

O resultado do influxo de indesejáveis, aproveitadores das disposições acomodatícias dos poderes públicos para penetrar com o pé esquerdo as portas da imigração indiscriminada, refletiu-se mais tarde no gangsterismo de Chicago e nos crimes e contravenções peculiares aos representantes da baixa classe de certas raças.

Em 1868 a América negociou com a China o tratado de Burlingame, outorgando amplas regalias aos chineses.

Uma nova fôrça introduziu-se na vida do continente americano, com a política dos altos salários. Havia entrechoque de interêsses de grandes proprietários, com empregados altamente assalariados, resultando dessa luta a falta de nacionais para a execução das tarefas mais pesadas.

Daí generalizar-se a avidez de mão de obra barata, encontrada nos grandes e necessitados contingentes estrangeiros, dispostos a trabalhar por qualquer preço².

2 John Rogers Commons - Races and Immigrants in America - Heath and Co., 1933, pags. 111-112. 
A situação de desigualdade de compensação do trabalho do alienígena feria a suscetibilidade dos intelectuais estrangeiros.

Luigi Villari profligava a emigração de seus compatriotas, asseverando que os italianos saíam de sua terra em bom estado de saúde e a ela retornavam invalidados por acidentes de trabalho, ou arruinados pelo trabalho em zonas insalubres e no interior de fábricas de condições higiênicas precárias. Tuberculose, sífilis, alcoolismo, e uma deplorável gíria, eram as principais exportações dos Estados Unidos para a Itália.

Apesar dessas invectivas, a opulência dos Estados Unidos continuou a atrair os imigrantes, provando que na riqueza e nas possibilidades econômicas de uma nação reside o principal fator de atração de alienígenas.

Os Estados Unidos, tradicionalmente democratas, sempre procuraram beneficiar-se com a crítica construtiva de seus cidadãos, empenhados na erradicação oportuna de erros ignorados pelo poder público, a fim de impedir, através do tempo, o prolongamento de suas conseqüências lamentáveis.

Já começara a imigração tumultuária a produzir seus nefastos resultados, quando a voz vigilante de Benjamin Franklin se fêz ouvir para denunciar a germanização da Pensilvânia: "Por que há de a Pensilvânia, terra fundada por inglêses, tornar-se ante nossas vistas, uma colônia de estrangeiros, que cedo serão tão numerosos a ponto de germanizar-nos, ao invés de serem por nós anglificados?"

A 3 de março de 1891, criava-se o "Bureau of Immigration" no Departamento do Tesouro, de onde foi transferido para o do Comércio e Trabalho em 14 de fevereiro de 1903. A 29 de junho de 1906, foram ampliadas as suas funções, cabendo-Ihe também as atribuições relativas a naturalização, passando então a chamar-se "Bureau of Immigration and Naturalization".

Mais tarde, em conseqüência do "Reorganization Plan V", aprovado em 4 de junho de 1940, passou para o "Department of Justice", tomando o nome de "Immigration and Naturalization Service". Cabe-Ihe a aplicação das leis sôbre imigração, assim como a identificação e registro de todos os estrangeiros residentes em terras norte-americanas.

O exame de casos de expulsão e extradição, e a imposição de multas às companhias de navegação infratoras de dispositivos legais sôbre o assunto, estão a cargo do "Board of Immigration Appeals", órgão integrante do "Office of the Attorney General" do Departamento de Justiça.

A coleta de informações sôbre a conveniência da introdução de imigrantes, levando em consideração os interêsses nacionais, assim como a fixação de quotas, constituem atribuições do Departamento de Estado. O órgão incumbido dessas 
funções é o "Office of Controls", constituído de quatro divisões "Passport Division", "Visa Division" (exercendo funções relacionadas com a imigração), "Special War Problems Division" e "Division of Foreign Activities Correlation" (incumbidas do estudo dos casos provenientes de relações decorrentes do estado de guerra, tais como troca de prisioneiros, repatriação de cidadãos americanos, etc., e, ainda, da articulação entre as atividades executadas pelo departamento a que pertencem os Departamentos de Guerra e Marinha) ${ }^{3}$.

A nosso ver, a orientação norte-americana no trato dêsses problemas encerra uma idéia digna de aproveitamento: a proximidade entre a imigração e a naturalização, confiadas a um mesmo órgão, com vistas, é claro, a uma intensiva nacionalização.

A variabilidade da condição do estrangeiro através dos séculos é de molde a demonstrar a fragilidade dos alicerces em que os governos têm baseado a sua ação no tocante à imigração.

Nota-se a falta de um plano sistemático e suficientemente detalhado, em que sejam nìtidamente fixados os objetivos visados com a introdução de imigrantes, e provendo a sua seleção segundo critérios preestabelecidos.

As enormes exigências do mercado de trabalho brasileiro e a vizinhança de uma nova era econômica, de trabalho e prosperidade, reclamam a abertura de nossas portas ao estrangeiro, sem prejuízo, evidentemente, das medidas acautelatórias necessárias para evitar a incidência em erros condenados por experiências anteriores.

É chegada a hora de fazer ouvidos de mercador ao brado dos adversários da imigração, que se estribam no pretenso resguardo dos fatôres étnicos da nacionalidade. A imigração racionalmente dirigida, na qualidade de um ato voluntário de um país de pobre demografia que se debate angustiosamente na procura de braços, não pode ser temida como um fantasma ameaçador que venha desagregar a raça. Além disso, uma seleção bem feita e uma assimilação favorecida anulam os perigos representados pela impermeabilidade de certas raças. Os quistos raciais só aparecem quando a inércia dos poderes públicos permite o seu processo de formação.

Nenhuma raça é rigorosamente pura, e afirmar o contrário é incidir nas teses tão do agrado dos geo-políticos alemães. Esta é uma asseveração ociosa, em face do que diz Commons, sôbre a realização de amálgamas desde a idade da pedra.

\footnotetext{
3 Informações colhidas do "United States Government Manual", 1945, First Edition, pgs. 203-273-275-613619. Não nos prolongamos mais sôbre a enumeração das atribuições dos órgãos mencionados, porque é nosso propósito fazê-lo em estudo especialmente dedicado a êsse fim.
} 
A bolha de sabão do arianismo puro de Lapouge, Chamberlain, Gobineau, e outros adeptos do dolicocéfalo louro como padrão de "homosapiens", apesar de nascida como um movimento científico, acabou por empolgar o espírito germano, que precisava de uma justificativa para os seus excessos nacionalistas e suas tendências dominadoras.

Já é, portanto, tempo de relegar a doutrina às ruínas do passado, em vista do sangue, suor e lágrimas que exigiu a destruição daquele mito.

Os argumentos da Ciência corroboram a inexistência de superioridades raciais. Os Drs. Bertha M. Boody e Edmund de S. Brunner realizaram testes psicológicos em filhos de fazendeiros imigrantes e crianças imigradas para os Estados Unidos, concluindo, da comparação entre as possibilidades mentais dos diferentes grupos raciais, pela inexistência de quaisquer inferioridades quanto à facilidade de apreensão, habilidade, etc. ${ }^{4}$

Os americanos não se pejam em reconhecer que sem o trabalho do imigrante as suas estradas de ferro não se teriam construído tão ràpidamente, nem se teria erguido, desenvolvido e mantido o seu extraordinário poderio industrial.

Achamos que o nosso país bem poderia valer-se da experiência dos Estados Unidos neste particular, dado que as semelhanças entre os seus atuais problemas e os daquela nação, no passado, argumentam em favor de soluções análogas ${ }^{5}$.

A tremenda lacuna econômica representada pelo despovoamento rural reclama a afluência de novos elementos e as atenções dos poderes públicos para o restabelecimento do equilíbrio entre a população rural e a urbana em nosso país.

O abandono dos campos, pela falta de recursos dos camponeses, e o deslocamento dêstes para as cidades acarretam o crescimento desproporcional das metrópoles e o agravamento de seus problemas de manutenção.

As massas são atraídas pela vida falsamente ostentosa dos centros populosos, indo engrossar as fileiras dos que pululam à beira de uma prosperidade fictícia.

\footnotetext{
${ }^{4}$ Experiência narrada por Hannibal Gerald Duncan (Immigration and Assimilation - Heath and Co., 1933, pág. 490).

${ }^{5}$ Êste é também o ponto de vista do ilustre Dr. Arthur Hehl Neiva, que na sua magnífica tese intitulada "O problema imigratório brasileiro" (Publicada na "Revista de Imigração e Colonização", set. 1944, pág. 458) declara: (pág. 525) “... mas como havia possibilidades quase ilimitadas de prosperidade e progressos pessoais, desde que se desejasse realmente trabalhar com intensidade, para aquele país foi atraída a maior imigração de toda a história por ser uma nação democrática, onde as diferenças de sangue ou de condições econômicas nada significavam para quem desejasse, pelo seu esforço, contribuir para o desenvolvimento geral dos Estados Unidos. É extremamente difícil traçar um paralelo adequado entre os Estados Unidos e Brasil. Entretanto, as oportunidades existentes no Brasil de hoje não são menores do que as apresentadas pelos Estados Unidos de 1870". (é nosso o grifo).
} 
São as chamadas tendências rurífugas, tão bem analisadas num trabalho do Dr. Fernando Mibieli de Carvalho ${ }^{6}$.

A política imigratória orientada no sentido de povoamento do "hinterland", promovendo a fixação do homem à terra, identificando o campônio com novos processos agrícolas, servirá para estender-Ihe os benefícios de ordem material e intelectual até agora adstritos ao âmbito dos grandes centros urbanos, obviando os fatais inconvenientes do absenteísmo rural.

Mas não estamos muito certos das possibilidades imigratórias de após-guerra. A Comissão de Imigração da Conferência de Havana acha que "o empobrecimento considerável dos povos europeus, depois da guerra, criará fortes necessidades de emigração e aumentará a atração que sôbre êsses povos tem exercido o hemisfério ocidental".

Roosevelt, em 1939, prevendo os enormes deslocamentos que iriam exigir as atividades bélicas, prognosticava, para um mundo livre das ameaças totalitárias e quintacolunistas, a atenuação das considerações de ordem demográfica, étnica e política, predominantes depois da primeira guerra mundial.

Supomos, todavia, não obstante a atual depressão dos povos europeus, que os países duramente atingidos pelo látego da guerra não poderão abrir mão de seus trabalhadores, mais do que nunca necessários ao soerguimento de suas nacionalidades.

O entendimento recíproco entre os países de emigração e os de imigração faz parte das novas concepções a que fizemos referência no início destas considerações. A imigração é um problema irremediavelmente preso a soluções internacionais, pois só dêste modo as transfusões de sangue europeu para a América tenderão a uma distribuição mais eqüitativa do fator humano sôbre a terra, de conformidade com os supremos interêsses da humanidade ${ }^{7}$.

O Brasil se ressente, neste momento, da ausência de uma organização administrativa capaz de arcar com as responsabilidades que acompanham a ampla introdução de braços estrangeiros. Perduram ainda dúvidas sôbre o tipo de organização necessário à solução do assunto, tendo êste, aliás, constituído motivo

\footnotetext{
6 O trabalho, que é realmente interessante, intitula-se: "O êxodo rural" e foi publicado na " Revista de Imigração e Colonização", dezembro, 1942, pag. 9.

7 Recomendamos ao leitor o trabalho do Sr. Fischlowitz, já citado, no qual focaliza com bastante agudeza êste aspecto da questão.
} 
para uma das recomendações da Conferência de Teresópolis, que chegou a optar pela criação de um Ministério de Povoamento, solução adotada com bons resultados em outros países.

A nosso ver, a principal necessidade é de que uma ação segura e objetiva proceda ao reajustamento das peças do organismo administrativo existente, seguida da racionalização das normas jurídicas reguladoras do assunto, o que se poderá conseguir mediante uma criteriosa consolidação, ou mesmo, elaboração de um Código de Imigração e Colonização.

Êste é, seguramente, um meio de amparar o Brasil na sua marcha rumo à industrialização de suas fôrças, rumo à posse de si mesmo, rumo ao reconhecimento de sua maioridade política e econômica, rumo, enfim, a uma nova era de prosperidade, em que o bem-estar da coletividade seja o reflexo ampliado do bem-estar de cada indivíduo. 